\title{
LITERATURA Y MITO: DESMITIFICACIÓN, INTERTEXTUALIDAD, REESCRITURA
}

\author{
LITERATURE AND MYTH: DEMYTHOLOGIZING, \\ INTERTEXTUALITY, REWRITING
}

\section{Luis MARTÍNEZ-FALERO}

\author{
Universidad Complutense de Madrid \\ Imartinezfalero@filol.ucm.es
}

Resumen: En este artículo se propone un estudio acerca de los procesos de desmitificación y reescritura del mito etno-religioso y del mito literario (tras la confluencia de ambos en el imaginario occidental), con una tipología de los modos de reescritura del mito.

Abstract: A study about the processes of demythologizing and rewriting concerning anthropological and literary myths (after their confluence in the western imaginary) is proposed in this article. It includes a typology of the different patterns of rewriting myths.

Palabras clave: Imaginario literario. Mito. Desmitificación. Reescritura. Intertextualidad. Literatura Comparada.

Key Words: Literary imaginary. Myth. Demythologizing. Rewriting. Intertextuality. Comparative Literature. 
El mito ha desempeñado, desde siempre, un papel crucial en las sociedades humanas, como podemos encontrar atestiguado en inscripciones y figuras talladas desde el Paleolítico Medio y en formas más complejas (con una correspondencia evidente con rituales más complejos) desde el Neolítico y la Edad del Bronce. Mucho más allá del símbolo, el mito ha configurado el pensamiento de esas sociedades, ha permitido explicar fenómenos naturales, generalmente ligados a rituales (por ejemplo, en Eleusis o en Abidos, con cultos establecidos en el segundo milenio antes de nuestra Era, con la cosecha como referente), o como memoria de lo que Eleazar Meletinski denomina los protoantepasados (2001: 169-184), o antepasados míticos de una estirpe o un pueblo, lo que acogería tanto el culto a los antepasados familiares como la divinización de héroes y reyes de origen indoeuropeo, según la doctrina de Georges Dumézil (2006). Pero también el mito ha servido, y sirve, para explicar nuestra naturaleza, al materializar nuestras pulsiones o esos elementos profundamente humanos que duermen en nuestro inconsciente, como señaló Carl Gustav Jung en varios de sus trabajos ${ }^{1}$. Así, la pulsión sexual, la pulsión de muerte, pero también nuestros temores y nuestras experiencias más profundamente humanos, se han venido materializando en forma de arquetipos que nos han permitido reconocernos en esas personificaciones, para comprender mejor nuestra naturaleza (Frye 1977: 139-145). Ahora bien, el componente psicológico, a la hora de estudiar el mito, también aúna el componente antropológico, pues Jung había partido de los trabajos de Lucien Lévy-Bruhl, igual que unas décadas antes Théodule Ribot había empleado los de Max Müller en su Essai sur l'imagination créatrice (1900: 100-103). Porque el mito desempeña una función social básica: cuando esta función deja de producirse, a causa de los cambios de mentalidad o por agotamiento (es decir, por la automatización del mito), éste es sustituido o desaparece.

Ahora bien, las sociedades generan dos tipos de mitos culturales: por una parte, los mitos etno-religiosos, ligados a rituales y con un papel fundamental en las creencias de una sociedad; y los mitos literarios, creados por la individualidad a imitación de los anteriores, pero que pasan al imaginario de una comunidad hasta formar parte de su inconsciente colectivo. Ambos tipos de mito acaban por confluir, por su carácter narrativo, entrando a formar parte del corpus literario de una determinada tradición. Sobre ello basamos este estudio, delimitando lo etno-religioso de lo literario, estudiando la confluencia de ambos a través de la visión histórica de los procesos de desmiti-

\footnotetext{
${ }^{1}$ Para una visión de conjunto de la obra de Jung, puede verse Jasionowicz (2005).
} 
ficación en el imaginario occidental y mediante una tipificación de las posibles reescrituras del mito en la literatura contemporánea.

\section{MITO Y LITERATURA: UNA PERSPECTIVA HISTÓRICA}

Los mitos etno-religiosos y los mitos literarios constituyen una parte fundamental de nuestro imaginario. Como es evidente, existen notables diferencias entre uno y otro tipo de mito. Frédéric Monneyron y Joël Thomas (2002: 58-59) establecen seis caracteres distintivos del mito antropológico, respecto del mito literario: 1) Su origen se produce en un pasado remoto; 2) es una formación colectiva y oral; 3) describe la irrupción de lo sagrado o sobrenatural en el mundo; 4) su sentido es simbólico; 5) corresponde a una forma primitiva de especulación filosófica; y 6) constituye un relato paradigmático.

Partiendo de esta distinción, Claude de Grève (1995: 42) estableció cuatro características del mito literario: $1^{\text {a }}$ ) Se trata del desarrollo de un contenido a través de un relato, susceptible de variaciones mediante su reformulación y lectura a lo largo del tiempo; $2^{\mathrm{a}}$ ) la relación entre el relato y lo sobrenatural o lo inexplicable, que se aproxima a lo irracional; $3^{\mathrm{a}}$ ) el mito literario desvela verdades ocultas al lector a través de su carácter simbólico, pudiendo transgredir de esta manera algunas normas sociales; y $4^{\mathrm{a}}$ ) el mito literario puede variar su significación a lo largo de la historia, las culturas, los autores y los lectores, de tal modo que su plurivocidad es creciente. Por su parte, Philippe Sellier (1984) estableció cinco grupos de mitos literarios:

a) Relatos de origen mítico consagrados en el panteón cultural occidental, de tal manera que suponen el marco del mito literario.

b) Mitos literarios nuevos, surgidos a lo largo del siglo XII (como Tristán e Iseo), en el siglo XVI (como Fausto), en el siglo XVII (como Don Juan), etc.

c) Relatos desarrollados a partir de lugares que quedan fijados en la imaginación (incluida la colectiva), pero que no presuponen una situación determinada.

d) Mitos político-heroicos, en los que se trata de la mitificación de figuras históricas, como Alejandro, César, Napoleón, etc. También de acontecimientos reales o semi-reales: la Guerra de Troya, la Revolución Francesa... Aquí el mito remite a las personalidades (Helena o 
Aquiles, por ejemplo) o a grupos (los revolucionarios), según el proceso característico de un género literario bien conocido: la epopeya.

e) Mitos parabíblicos, surgidos a veces de un versículo (Lilith, Golem, los ángeles, los jinetes del Apocalipsis...), cuya existencia nos indica que la mayor parte de los mitos literarios se han impuesto a partir de una sola aparición.

Pero, como señala Marie-Catherine Huet-Brichard (2008: 42-44), existe un nexo entre ambos tipos de mito: su narratividad, que ya nos mostraba la etimología griega de 'mito', al designar un 'relato'; en el caso del mito literario, ese relato, de manera progresiva a lo largo de la diacronía, será la suma de todas sus versiones, que acaban por configurarlo.

Esta narratividad supone que, una vez perdida su función o su referente de naturaleza religiosa (esto es, su vinculación a un ritual), el mito pase a ser una historia ficcional más, como cualquier relato. De este modo, la creencia deja su lugar a la literatura, fundiéndose la narración mitológica en el corpus textual de una tradición literaria. Sin embargo, históricamente esto no es nuevo, sino que supone una constante desde el final de la Edad del Bronce, cuando - por ejemplo - los dioses locales micénicos fueron cediendo su lugar a la koiné del panteón griego, quedando sus nombres a veces como complemento del nombre de un dios o una diosa en un culto local determinado y otras veces directamente en el olvido (Bermejo Barrera y Reboreda Morillo, 1996: 17-22), como la diosa micénica Potnia (diosa de la fecundidad o la abundancia), que aparece ligada posteriormente a Deméter o a Artemisa en forma de apelativo local. No obstante, algunas divinidades micénicas (con culto propio) desaparecieron, suponemos que junto a sus respectivas fábulas mitológicas (Chadwick, 1976: 95-102; Schofield, 2007: 159-161). Por tanto, la sustitución o la desaparición de dioses y diosas del Bronce Antiguo y Medio se irá produciendo a lo largo de un período que desemboca, tras la Edad Oscura (1200-1100 a.C.), en Homero y en Hesíodo (siglos VIII y VII a.C., respectivamente), quienes marcan ya la tradición mitológica que vamos a hallar en la literatura posterior, con las correspondencias evidentes en el mundo latino, aunque incluso un siglo después de Hesíodo siga existiendo en Grecia una cierta duplicidad, como ese «Zas» (Zeus) del que nos habla Ferecides de Siros en su Teogonía (fr. 1-8) (Freeman, 1948: 14).

No obstante, ya desde el comediógrafo Estesícoro (siglos VII-VI a.C.) o el presocrático Jenófanes de Colofón (siglo VI a.C.), existe un intento racionalista de explicación de la tradición mitológica griega, a lo que hay que unir la atribución de un origen histórico y social a los mitos, efectuada por 
Evémero (entre los siglos IV-III a.C.) (Nestle, 2010: 82-90) o la lectura alegórica que lleva a cabo el estoico Crísipo (siglo III a.C.), para quien los dioses son alegorías basadas en la personificación de elementos naturales, de tal modo que - por ejemplo-Zeus representa el espíritu del mundo (Crísipo, 2006: 283-284).

Toda esta tradición racionalista griega (sobre todo la de raíz estoica) desemboca en el mundo latino en Cicerón, quien une - además - esa cierta animadversión de Platón y Aristóteles hacia la alegoría y sus diversas manifestaciones textuales ${ }^{2}$. En su tratado Sobre la naturaleza de los dioses, el Arpinate reescribe y corrige la Teogonía de Hesíodo (Teogonía 214-225). Veamos como ejemplo la genealogía de la diosa Noche en el autor griego:

Parió la Noche al maldito Moros, a la negra Ker y a Tánato; parió también a Hipnos y engendró la tribu de los Sueños. Luego además la diosa, la oscura Noche, dio a luz sin acostarse con nadie a la Burla, al doloroso Lamento y a las Hespérides que, al otro lado del ilustre Océano, cuidan las bellas manzanas de oro y los árboles que producen el fruto.

Parió igualmente a las Moiras y las Keres, vengadoras implacables: a Cloto, a Láquesis y a Átropo que conceden a los mortales, cuando nacen, la posesión del bien y del mal [...]

También alumbró a Némesis, azote para los hombres mortales, la funesta Noche. Después de ella tuvo al Engaño, la Ternura y la funesta Vejez, y engendró a la astuta Eris [...] (Hesíodo, 1990: 80).

Aparte de que sorprenda el que en esa enumeración de sustantivos con connotaciones negativas («engaño», «vejez»y «discordia») se incluya la «ternura», quizá para atenuar un poco esa conjunción de elementos, Cicerón intenta poner algo de sentido común en una teología latina sobresaturada. Y, así, nos dice (De natura deorum 3.17.44):

Si éste [Saturno] es un dios, ha de reconocerse que también lo es su padre, Cielo. Si esto es así, también los padres de Cielo han de ser tenidos por dioses, Éter y Día, así como sus hermanos y hermanas, a quienes los geneálogos antiguos denomina así: Amor, Engaño, Miedo, Fatiga, Envidia, Destino, Vejez, Muerte, Tinieblas, Miseria, Queja, Gracia, Fraude, Obstinación, Parcas, Hespérides y Sueños. Cuentan que todos ellos nacieron de Érebo y Noche. Por tanto, o bien ha de ratificarse la existencia de estos monstruos, o bien ha de eliminarse la de aquellos primeros (Cicerón, 2000: 306).

\footnotetext{
${ }^{2}$ V.gr. Platón, Fedro 229b-230a o Epínomis 974e-975c. Aristóteles, Metafísica 1093a27.
} 
No obstante, a pesar de Cicerón, la Noche y su descendencia ocupa un lugar destacado en la literatura latina, quizá no sólo por el peso de la tradición hesiódica, sino también por el empleo de estos actantes mitológicos, sobre todo Noche (Nyx) y Sueño (Hypnos) en el «Canto XIV» de la Ilíada (en un grupo de versos que se extiende del 231 al 276), cuando Hera invoca al dios Sueño; por su parte, la Muerte (Thánatos), aparece unida al Destino (Moira) en el «Canto III» (verso 101) y en el «Canto XVI» (verso 853). Por ello, no es extraño que la épica latina también los utilice, tanto en el caso de Virgilio (cuya Eneida está directamente inspirada en Homero), como - un siglo más tarde - en la Tebaida de Estacio ${ }^{3}$. Pero en este período, entre el siglo I a.C. y el primero de nuestra Era, las contradicciones respecto del mito nos darán como resultado, por una parte, el juego puramente literario establecido entre los mitos, que hallamos en las Metamorfosis de Ovidio, obra en la que se concatena el corpus completo de fábulas mitológicas a partir de un elemento común entre dos o más de estas narraciones, y la visión plenamente ortodoxa del mitógrafo Aneo Cornuto, quien, unas décadas más tarde, nos dice respecto de la Noche: «De Caos es hija también la Noche, pues el aire primordial que se alzó de la humedad primigenia era brumoso y oscuro; luego, al volverse más liviano, se transformó en éter y luz, y con buen sentido se dijo que éstos habían nacido de la noche» (2009: 229-230). Es más, a partir de la época de Augusto (la época dorada) no son extrañas las transferencias de atributos, ritos o mitemas entre dioses y diosas de Roma y otras deidades anteriores de origen oriental, como sucede con esa Venus funeraria, que acoge rasgos de la fenicia Astarté, idénticos a los de sus equivalentes en Sumer (Inanna), Asiria (Ishtar) o en la mitología cananea (Astarot), al responder a la duplicidad fecundidad-regeneración en el Oriente Próximo (Picard, 1939: 130-131); aunque esta asimilación entre Venus y Astarté se produjo de manera parcial o - mejor dicho- superficial.

Paralelamente a este proceso sufrido por los mitos etno-religiosos griegos y romanos, encontramos el declive de los mitos heroicos procedentes de la épica o la tragedia, cuya degradación permitirá aflorar a los nuevos arquetipos de la novela griega (siglos II a.C.-V d.C.) y latina (siglos I y II d.C.) (García Gual, 1972: 121-123).

En el contexto de la otra gran fuente del imaginario (literario) occidental, la Biblia, encontramos - por ejemplo - la reescritura del arquetipo de Daniel, procedente de la tradición asirio-babilónica, donde es un rey, padre del héroe Aqhat, asesinado por la diosa Anat tras un intento fallido de se-

${ }^{3}$ Virgilio, AEneidos 3.512, 5.721, 5.738, 5.835, 7.138 ó 12.846. Estacio, Thebaidos 1.96 ó 6.27. 
ducción por parte de esta hermana-esposa de Baal; Daniel consigue la justicia divina, por lo que gozó de una gran popularidad tanto en la tradición ugarítica como en la posterior babilónica (Del Olmo, 1998: 211-245). Este arquetipo fue importado al imaginario judío en forma de profeta en tierras de Babilonia, pasando a nuestro imaginario, principalmente a través del episodio en el foso de los leones (Dn 14, 31-42). El apocalipsis contenido en este libro del Antiguo Testamento (Dn 11, 40 y ss.) resulta también interesante, pues los relatos apocalípticos (alegóricos y con suficientes elementos simbólicos como para ser leídos como fábulas mitológicas antitéticas de los mitos de la creación) proceden de la tradición religiosa babilónica, conociendo diferentes reescrituras en la literatura judía pre-cristiana ( «El libro de los Vigilantes», «Apocalipsis de las diez semanas del mundo», «Libro de los secretos de Henoc»...), pasando a la tradición cristiana no sólo a través del Apocalipsis de San Juan, sino de otros textos apócrifos como los apocalipsis atribuidos a los apóstoles Pedro o Tomás, o el atribuido a San Pablo (Piñero, 2007). Obviamente, esta tradición ha conocido diferentes reescrituras a lo largo de la diacronía literaria, incluyendo los relatos visionarios de ermitaños a lo largo de la Edad Media o los más recientes sobre apocalipsis nucleares.

Con la llegada del Cristianismo, el mito clásico fue sustituido progresivamente por arquetipos cristianos, como nos muestra Philippe Walter en su Mitología cristiana (2004), reemplazando el imaginario grecolatino por el hebreo, formado por nuevas figuras tomadas del Antiguo y del Nuevo Testamento y por referentes reales extraídos del martirologio y otras fuentes (como el mito oriental transformado en la vida de San Jorge), lo que desembocará en la Leyenda áurea, de Jacobo de Vorágine, en el siglo XIII.

En el contexto cristiano, el mito clásico se moralizó para servir como vehículo doctrinal al mismo nivel que la literatura. El origen de esta utilización de elementos de la religión grecolatina en la nueva religión lo hallamos, por ejemplo, tanto en la sustitución de un rito por otro, atendiendo al carácter salvífico de ambos, o a la aparición de las mismas especies rituales (trigo y vino), como a la reutilización de textos oraculares transformados en proféticos, como sucede con las profecías de Apolo en el contexto de la Patrística griega de los primeros siglos del Cristianismo (Herrero de Jáuregui, 2007; Nieto Ibáñez, 2010). La nueva lectura moral del mito apareció de la mano de Clemente de Alejandría en el siglo III y se convirtió en un modelo de trasmisión doctrinal que, sin modificar en lo textual el imaginario occidental, introducía nuevos conceptos en él, lo que podemos comprobar a lo largo de toda la Edad Media en las literaturas europeas. Buena prueba de ello son los ovides moralisés que, desde Francia, van a ser un constante referente en la Edad Media y el 
Renacimiento, o bien a través de traducciones, o bien a través de exégesis de diverso tipo, junto a la De genealogia deorum gentilium de Boccaccio, obra no exenta de comentarios morales y que conocerá diversas ediciones, adaptaciones y secuelas a partir del siglo XV en toda Europa. Este proceso de moralización del mito concluye con los procesos de desmitificación que, a partir del empleo de la cita referencial mitológica en la literatura profana de los siglos XV, XVI y XVII, alcanzará su culminación en esa última centuria en toda Europa, fruto de las críticas luteranas - por una parte - y de las efectuadas por moralistas católicos - por otra-, que desembocan en la práctica persecución de la literatura sospechosa de paganizante tras el Concilio de Trento (Martínez-Falero, 2011: 61 y ss.). Esta culminación del empleo del mito se manifestará o bien en su empleo por parte de la poesía satírica (española, francesa e italiana, principalmente), lo que deviene en la desmitificación, o en la literatura religiosa (Orfeo, Hércules e incluso Narciso como alegorías de Cristo), que agota las lecturas posibles de la fábula mitológica clásica.

No obstante, el mito reaparece periódicamente en la literatura, como actante de tipo comparativo (mediante la amplificación o la reinterpretación de un mitema ${ }^{4}$ característico del arquetipo original), o bien a través de una lectura sentimental del mito o, incluso, como un elemento convencional más de la tradición literaria que sirve como referente al escritor en su actividad creativa, por lo que formaría parte de su memoria textual, que actuaría (en este caso) para el desarrollo de la escritura como actividad mitopoética. En cualquiera de estos casos, la reescritura del mito está ligada a la intertextualidad y, de cualquier modo, siempre partiríamos de la descontextualización y recontextualización del arquetipo (o de alguno de sus mitemas), como forma de actualizar las lecturas posibles de los arquetipos ya tradicionales en un corpus textual determinado. Por tanto, desmitificación e intertextualidad aparecen como los procedimientos esenciales para la reescritura del mito.

\section{DESMITIFICACIÓN E INTERTEXTUALIDAD: DESCONTEXTUALIZACIÓN Y RECONTEXTUALIZACIÓN DE LA FÁBULA MITOLÓGICA}

Si seguimos la teoría sobre la desmitificación elaborada por Hans Ulrich Gumbrecht (quien parte de conceptos lingüísticos al corresponder los ar-

\footnotetext{
${ }^{4}$ Utilizo aquí ‘mitema' como cada una de las frases mínimas particulares en que se descompone el relato de un mito, según la definición de Claude Lévi-Strauss (1974: 235-265).
} 
quetipos míticos a conceptos morales o modelos humanos), podemos realizar una tipología de los procesos de desmitificación, que él formula de la siguiente manera:

Bajo una perspectiva semántica, desmitificación hace referencia a la reformulación de un mito, reformulación que, como una irrupción en el nivel fenoménico de la designación (tomada aquí en un sentido amplio), debería dejar lo más inalterado que pudiese el significado del mito mismo o el «acto de habla» por él realizado. Bajo una perspectiva pragmática, el predicado desmitificación designa una recepción de mitos llevada a cabo bajo un punto de vista y por medio de unos actos de comprensión tales que, en un contexto de comunicación «primario» y de «coherencia mítica», no tendrían lugar posible. Cualquier otro tratamiento del mito, también el científico, enmarcado fuera de este contexto auténtico de aplicación viene a ser desmitificación en un sentido pragmático. Bajo esta perspectiva pragmática, y al contrario que bajo la perspectiva semántica, desmitificación supone la posibilidad de dejar inalterada la concretización textual de los mitos (Gumbrecht, 1992: 281-282).

Además, Gumbrecht distingue entre una desmitificación no intencional, producida por un proceso histórico, en el que la transmisión de contenidos culturales transfiere mitos a un contexto social distinto, y una desmitificación intencional, que se produce cuando se pretende eliminar algunos o todos los mitos en aras, por ejemplo, de un mayor desarrollo o una mayor implantación de la ciencia, como veíamos ya en Grecia (con Jenófanes, por ejemplo) y que será una constante en Occidente a partir del Empirismo y el Racionalismo cartesiano.

De este modo, podemos establecer diversas fases en la desmitificación no intencional de arquetipos clásicos, ampliando la teoría de Gumbrecht:

1. El primer grado de desmitificación consiste en la descontextualización que supuso la llegada del Cristianismo, cuando los autores cristianos leyeron los arquetipos míticos al mismo nivel que los arquetipos literarios, realizando siempre una lectura moral, nueva función social de estos elementos tomados de la tradición clásica. Además, esta fusión de ambos tipos de mito, a partir de su narratividad, permitió crear nuevos modelos a imitación de éstos, que han de responder siempre a encarnar un rasgo humano esencial o a reflejar una cuestión profundamente humana, convirtiéndose así en símbolos complejos.

2. El segundo grado de desmitificación procede de la recuperación del mito a partir del Trecento italiano, cuyos imitadores harán retornar el mito a 
la literatura o bien a través de las nuevas versificaciones de la fábula mitológica (sobre todo en la tradición de Ovidio), lo que encuadraríamos en una desmitificación semántica (ideológica, pero no textual); o bien a través de la cita referencial, que supondría un segundo paso en la desmitificación pragmática. Este segundo empleo supone la descontextualización del mito, inserto en composiciones de temática diversa, y cuya única función es servir al ornato, trazando paralelos entre el asunto o los motivos desarrollados en los textos y algunos referentes clásicos. Aquí los arquetipos míticos y los arquetipos literarios clásicos sufren ya el mismo proceso. De este modo, sobre todo en la poesía, los arquetipos clásicos establecen correlaciones semánticas al aparecer unidos en el mismo contexto textual, sea por la analogía establecida entre ellos a partir de algún mitema parecido, sea por una nueva relación determinada por el poeta al escribir su obra: por ejemplo, el asunto de un poema puede unificar (en el desarrollo de un tema) la fábula de Leandro y Hero, la de Orfeo y Eurídice y la de de Apolo y Dafne, junto a otros arquetipos. Aquí el mito ha perdido ya cualquier conexión con sus orígenes e incluso con el relato tradicional de su fábula mitológica, quedando reducido a unos pocos mitemas fundamentales, que, en muchas ocasiones, terminan por reducirse a un mitema esencial.

3 . El tercer y último grado de desmitificación es la inclusión de la cita referencial en la literatura satírica, donde se subvierte ese mitema esencial que ha sobrevivido de la fábula mitológica de procedencia. Este hecho suele venir acompañado de la parodia, en la que se recoge la lectura de la fábula mitológica establecida por los moralistas cristianos, quienes rechazan los arquetipos clásicos y se ocupan en demostrar lo absurdo o inmoral de sus acciones. Otra vía es la alegorización, convirtiendo los arquetipos clásicos en modelos cristianos. En ambos casos la desmitificación concluye con la automatización y agotamiento del mito como actante literario. Desde el punto de vista de la estética de la recepción, si la pervivencia del mito se había producido por un acercamiento entre el horizonte del relato mítico en el pasado y el horizonte de los lectores en un presente dado, la desmitificación motivada por esa automatización - vendrá como consecuencia de la ruptura de ese horizonte, quizá en espera de una nueva funcionalidad en el futuro (Mortier, 1994: 148).

Esta nueva funcionalidad consiste en la puesta en práctica de unos procedimientos creativos en la literatura, donde vendrá dada la transformación de elementos convencionales (formales, estéticos, etc.), entre los que se encuentra la tradición de arquetipos literarios (que, como ya hemos indicado, incluye los mitos clásicos), entendidos como motivos, susceptibles de tema- 
tizarse en algunos casos, tal como sucede también con los tópicos literarios. La intertextualidad aquí puede tratarse por la amplificación o síntesis de la cita, por la descontextualización del arquetipo originario o por la repetición de estructuras, es decir, por la identidad entre estructura del mito y estructura del texto establecida por Pierre Brunel (1992: 61).

De este modo, el mito, como cualquier otro discurso, se inserta en el texto literario de manera material (reproducción de palabras), estructural (reproducción de reglas) o de manera material-estructural (palabras y reglas) (Plett, 1991: 7), a partir de los mecanismos de escisión (con la subsiguiente descontextualización respecto del relato original) e inserción en un nuevo contexto, que caracteriza cualquier concurrencia intertextual, siempre con la presencia del lector, quien ha de relacionar ambos contextos (Martínez Fernández, 2001: 94). En el caso del mito, esta transferencia intertextual de unos textos a otros le permite mantener su vigencia, ya que, como señala Danièle Chauvin, «la intertextualidad es incluso en muchos casos uno de los procesos fundamentales para la edificación, es decir, para la perennidad del mito» (Chauvin, 2005: 175). Por esta pervivencia del mito, descontextualizado con relación a su relato original, desembocamos en la actividad creadora como momento en que recobra su actualidad, por cuanto la creatividad supone una actividad mitopoética (Wunenburger, 1994a: 50; y 1994b: 34-35; Thibault Schaefer, 1994: 61), en la que el mito se puede convertir o bien en un elemento significativo del texto o bien en la base misma del nuevo texto creado.

Por ello, consideramos aquí una posible tipificación de la reescritura del mito en la literatura contemporánea, como actividad mitopoética, aportando algunos ejemplos. Partimos de la lectura que Raymond Trousson realizó del mito de Prometeo y sus reescrituras en la literatura contemporánea, sea con una finalidad transgresora o una visión sentimental por parte de los escritores que se han venido inspirando en él (Trousson, 2001). Por otra parte, nuestra consideración acerca de las posibles reescrituras es paralela y complementaria a la establecida por Marc Eigeldinger con relación a la actividad intertextual en la literatura contemporánea, con el mito en el centro de su estudio, y que él formula a partir de cinco posibles concurrencias intertextuales: 1) El campo de la literatura, por ejemplo, con la aparición de versos ajenos en obras en prosa, como la inserción de versos de Petrarca en la Nueva Eloísa; 2) el campo artístico, mediante referencias fundamentales a obras de las distintas artes en una obra literaria, como el cuadro de Rubens «El descendimiento de la cruz» en Mademoiselle Dafné de Gautier; 3) el campo mítico, con la concurrencia de arquetipos procedentes del mundo 
clásico o literario como personajes de obras contemporáneas, como Fausto en la poesía de Valéry; 4) el campo bíblico, por ejemplo, en Una temporada en el infierno de Rimbaud; y 5) el campo de la filosofía, como hallamos en la producción de ficciones de Voltaire (Eigeldinger, 1987: 15-16). Junto con las funciones referencial y estratégica de la intertextualidad, plantea una función transformativa y una función semántica, consistentes tanto en la modificación del texto de origen como en la adquisición de nuevas significaciones de ese texto, para construir o completar la significación de esa nueva obra literaria en la que se integra (Eigeldinger, 1987: 17). Son éstas últimas las dos funciones de las que partimos al establecer estas modalidades de reescritura, que he fijado en cinco, teniendo en cuenta siempre la descontextualización de los arquetipos o relatos mitológicos:

1. Reescritura por adición de mitemas, cuyo modelo podría ser la reescritura histórica del mito de Fausto a partir del texto del siglo XVI, con las aportaciones de Marlow, Goethe, Klinger, Lernau, Thomas Mann o la realizada por la Fura dels Baus en su Fausto 2.0.

2. Reescritura por combinación de mitemas, que permite la generación de nuevos arquetipos, asumiendo rasgos o elementos de la trama de otros anteriores, como sucede en el siglo XIX con el arquetipo de la mujer fatal (Eetessam, 2009), cuyos mitemas van a consistir en una combinación de rasgos procedentes de Pandora y/o Lamia y/o sirenas y/o Lilith y/o Eva y/o Salomé y/o Judith...

3. Reescritura por subversión de mitemas, en la que podemos citar las obras paródicas de fábulas mitológicas que hallamos en el siglo XVII, de Francisco de Castro (y sus Metamorfosis a lo moderno) al Virgile travesty de Scarron, hasta desembocar, por ejemplo, en el Ulysses de James Joyce (1922) o en El retorno de Ulises (1946) de Gonzalo Torrente Ballester o en ¿Por qué corres, Ulises? (1975) de Antonio Gala, tanto en el aspecto estructural como en la subversión del arquetipo protagonista, según la creación particular de cada autor (Arroyo, 2010); o esa reescritura ex contrario de la Odisea que hallamos en la obra póstuma de Thomas Wolfe You Can't Go Home Again (1940).

4. Reescritura por analogía respecto de la estructura del relato, recogiendo así la teoría de Pierre Brunel. Como ejemplo podemos citar la estructura del laberinto (que nos remite al mito de Minos) que podemos hallar en El aleph de Borges, L'emploi du temps de Butor, o incluso en la obra poética de Edmond Jabès, al insertar poemas (poemas en prosa o en versículo, siempre con carácter discursivo o narrativo) e incluso secciones de unos li- 
bros en otros, hasta trazar un mapa poético donde cientos de caminos se cruzan y se separan.

5. Reescritura por analogía respecto de la trama del relato, en la que, en este caso, la posibilidad de inferencia por parte del lector desempeña un papel fundamental, al reconocer, a través de su memoria textual, rasgos de otros textos en un texto en particular. En este sentido, podemos citar como modelo Diálogo secreto (1984) de Buero Vallejo, donde el cuadro «Las hilanderas» de Velázquez es el objeto de estudio de un crítico de arte daltónico. La conexión entre la trama de esta obra dramática y la obra pictórica en torno a lo mitológico aparece en la tela de araña de mentiras sobre las que el protagonista ha tejido su existencia y la de su familia, con Aracné en el fondo del cuadro, tejiendo eternamente.

Queda fuera, como es evidente, una consideración desde el punto de vista del empleo de denominaciones de procesos psicológicos, que han sido etiquetados con nombres de mitos: el narcisismo (Freud / Lacan), el complejo de Edipo (Freud) o el complejo de Electra (Jung) parecen ser más bien materia de la psicocrítica (interpretar al personaje desde las correspondientes adscripciones clínicas) que considerar una posible reescritura del mito desde estas tipificaciones psicológicas.

En definitiva, la creación de mitos y la posterior descontextualización, desmitificación y reescritura son los ejes en torno a los que gira la actividad mitopoética, considerada en el contexto de los procedimientos creativos, donde nuestra memoria textual desempeña un papel esencial a la hora de introducir elementos intertextuales en los nuevos textos. La reescritura del mito nos viene dada también por una reformulación de la visión de la naturaleza humana y por los cambios sociales, producto de la evolución de nuestras sociedades y nuestras creencias, aunque siempre es posible encontrar constantes históricas (pulsiones o experiencias profundamente humanas), cuya reformulación es simplemente formal. Necesitamos simbolizar nuestro mundo para hacerlo tangible $\mathrm{y}$, en ese proceso, el mito configura nuestro imaginario, dinámico y rico en significaciones, pero que también nos devuelve - una y otra vez - a nuestros orígenes. 


\section{REFERENCIAS BIBLIOGRÁFICAS}

ARROYO MARTÍNEZ, L. (2010). La desmitificación de Ulises en el teatro de Antonio Gala. Madrid: Ediciones Clásicas.

BERMEJO BARRERA, J.C. y REBOREDA MORILLO, S. (1996). «Religión micénica y religión griega: problemas metodológicos». En Los orígenes de la mitología griega, J.C. Bermejo Barrera, F.J. González García y S. Reboreda Morillo, 5-40. Madrid: Akal.

BRUNEL, P. (1992). Mythocritique. Théorie et parcours. París: PUF.

CHADWICK, J. (1976). Mycenaean World. Cambridge: Cambridge University Press.

CHAUVIN, D. (2005). «Hypertextualité et mythocritique». En Questions de mythocritique. Dictionnaire, D. Chauvin, A. Siganos y Ph. Walter (dirs.), 175-181. París: Imago.

CICERÓN, M. T. (2000). Sobre la naturaleza de los dioses. Madrid: Gredos.

CORNUTO, A. (2009). Repaso de las tradiciones teológicas de los griegos. En Mitógrafos griegos, J. B. Torres Guerra (ed.), 187-278. Madrid: Gredos.

CRÍSIPO (2006). Testimonios y fragmentos. I. Testimonios. Fragmentos 1318. Madrid: Gredos.

DE GRÈVE, C. (1995). Éléments de littérature comparée. II. Thèmes et mythes. París: Hachette.

DEL OLMO LETE, G. (1998). Mitos, leyendas y rituales de los semitas occidentales. Madrid: Trotta.

EETESSAM PÁRRAGA, G. (2009). «Lilith en el arte decimonónico. Estudio del mito de la femme fatale». Signa 18, 229-249 (también en http://www.cervantesvirtual.com/obra/lilith-en-el-arte-decimonnico-estudio-del-mito-de-la-femme-fatale-0/).

EIGELDINGER, M. (1987). Mythologie et intertextualité. Ginebra: Slatkine.

DUMÈZIL, G. (2006). Mythes et dieux des indo-européens. París: Flammarion.

FREEMAN, K. (1948). Ancilla to the Pre-Socratic Philosophers, a complete translation of the fragments in Diels, Die Fragmente der Vorsokratiker. Oxford: Basil Blackwell. 
FRYE, N. (1977). Anatomía de la crítica. Caracas: Monte Ávila.

GARCÍA GUAL, C. (1972). Los orígenes de la novela. Madrid: Istmo.

GUMBRECHT, H. U. (1992). «Desmitificación». En Mythopoesis: literatura, totalidad, ideología, J. R. Resina (ed.), 281-299. Barcelona: Anthropos.

HERRERO DE JÁUREGUI, M. (2007). Tradición órfica y cristianismo antiguo. Madrid: Trotta.

HESÍODO (1990). Obras y fragmentos. Madrid: Gredos.

HUET-BRICHARD, M.-C. (2008). Littérature et mythe. París: Hachette.

JASIONOWICZ, S. (2005). «Archétype». En Questions de mythocritique. Dictionnaire, D. Chauvin, A. Siganos y Ph. Walter (dirs.), 27-40. París: Imago.

LÉVI-STRAUSS, C. (1974). Anthropologie structurale. París: Plon.

MARTÍNEZ-FALERO, L. (2011). Narciso en España: del origen a la desmitificación del mito. Madrid: Ediciones Clásicas.

MARTÍNEZ FERNÁNDEZ, J. E. (2001). La intertextualidad literaria. Madrid: Cátedra.

MELETINSKI, E. (2001). El mito. Madrid: Akal.

MONNEYRON, F. y THOMAS, J. (2002). Mythes et littérature. París: PUF.

MORTIER, D. (1994). «Mythe littéraire et esthétique de la réception». En Mythes et littérature, P. Brunel (comp.), 143-151. París: Presses Universitaires de Paris-Sorbonne.

NESTLE, W. (2010). Historia del espíritu griego. Barcelona: Ariel.

NIETO IBÁÑEZ, J. M. (2010). Cristianismo y profecías de Apolo. Los oráculos paganos en la Patrística griega (siglos II-V). Madrid: Trotta.

PICARD, G. Ch. (1939). «La Vénus funéraire des Romains». Mélanges d'archéologie et d'histoire 56, 121-135.

PIÑERO, A. (2007). Los apocalipsis. 45 textos apocalípticos apócrifos judíos, cristianos y gnósticos. Madrid: EDAF.

PLETT, H. (1991). «Intertextualities». En Intertextuality, H. Plett (ed.), 3-29. Berlín: De Gruyter. 
RIBOT, Th. (1900). Essai sur l'imagination créatrice. París: Felix Alcan.

SCHOFIELD, L. (2007). The mycenaeans. Londres: The British Museum Press.

SELLIER, Ph. (1984). «Qu'est-ce qu'un mythe littéraire?». Littérature 55, 113-126.

THIBAULT SCHAEFER, J. (1994). «Récit mythique et transtextualité». En Mythe et creation, P. Cazier (ed.), 53-66. Lille: Presses Universitaires de Lille.

TROUSSON, R. (2001). Le thème de Prométhée dans la littérature européenne. Ginebra: Droz.

WALTER, Ph. (2004). Mitología cristiana. Fiestas, ritos y mitos de la Edad Media. Buenos Aires: Paidós.

WUNENBURGER, J.-J. (1994a). «Mytho-phorie: formes et transformations du mythe». Religiologiques 10, 49-70.

- (1994b). «Principes d'une imagination mytho-poïtique». En Mythe et creation, P. Cazier (ed.), 33-52. Lille: Presses Universitaires de Lille.

Recibido el 13 de abril de 2012.

Aceptado el 30 de septiembre de 2012. 